\section{The $B D J$ top ten 2019}

The following is a list of the top ten most accessed BDJ articles published in 2019.

1. Periodontal diagnosis in the context of the 2017 classification system of periodontal diseases and conditions implementation in clinical practice https:// www.nature.com/articles/sj.bdj.2019.3

2. Charcoal-containing dentifrices https://www.nature.com/articles/ s41415-019-0232-8

3. Periodontal diagnosis in the context of the BSP implementation plan for the 2017 classification system of periodontal diseases and conditions: presentation of a pair of young siblings with periodontitis https://www.nature.com/ articles/sj.bdj.2019.2

4. A survey of stress, burnout and well-being in UK dentists https://www. nature.com/articles/sj.bdj.2019.6

5. Periodontal diagnosis in the context of the 2017 classification system of periodontal diseases and conditions: Presentation of a middle-aged patient with localised periodontitis https://www. nature.com/articles/sj.bdj.2019.45

6. Oral manifestations of sickle cell disease https://www.nature.com/articles/ sj.bdj.2019.4

7. Periodontal diagnosis in the context of the 2017 classification system of periodontal diseases and conditions: presentation of a patient with periodontitis localised to the molar teeth https://www. nature.com/articles/sj.bdj.2019.93

8. CariesCare practice guide: consensus on evidence into practice https://www.nature.com/articles/ s41415-019-0678-8

9. Periodontal care in general practice: 20 important FAQs - Part one https://www.nature.com/articles/ s41415-019-0374-8

10. Does articaine, rather than lidocaine, increase the risk of nerve damage when administered for inferior alveolar nerve blocks in patients undergoing local anaesthesia for dental treatment? A mini systematic review of the literature https://www.nature.com/ articles/sj.bdj.2019.98.

\section{BOOK REVIEW}

\author{
OXFORD ASSESS AND PROGRESS: CLINICAL DENTISTRY \\ Nicholas Longridge, Peter Clarke, Raheel Aftab, Tariq Ali; \\ 2019; \\ Oxford University Press; \\ price f23.99; pp. 314;
}

ISBN: 978-0-19-882517-3

Oxford assess and progress: clinical dentistry is a concise and comprehensive guide to dentistry, essential for the final years of dental school and postgraduate revision. The book gives a flavour of the crucial topics required for knowledge in exams and everyday work life, covering them in a compact concise book. I would recommend using it in the lead up to fourth and fifth year exams, after having done the bulk of revision. This will then help cement ideas and techniques learnt with evidence-based dentistry, and does so with practical application and real life scenarios.

Each of the 15 chapters represents one area of being a modern day dentist, and each has a bank of MCQ type questions. Where I found the book excelled was in its approach to telling you which answer is correct, not just explaining why, but also providing citations to papers and books to aid with further reading. With this approach, it encourages the reader to ask questions in their day-to-day work, and provides answers and sources to expand on knowledge. Each question is ranked on a four star scale, giving

the reader a level of complexity, from what final year dental students should know, to what foundation year dentists might like to know. The questions are very specific, and rather than asking the questions a dental student typically recites, test the reader and help them fully understand the subject. The book aids you in the pursuit of understanding the methods and mechanics involved in dentistry, better helping the reader to ask 'why is this working?' and 'what is actually happening?'

Reading through the book I found it would be useful for dental students later on in their studies, but also recently qualified dentists. It is very useful for postgraduate exams, giving the topics required and enabling you to grade how much knowledge you lack in a specific area. I would recommend this book as an essential revision book for students and post-graduates in their early years. With the book being small and concise, it is great to have in your pocket for whenever you have a spare ten minutes.

Sam Wareing

\title{
Student feedback needed
}

A research group at the Eastman Dental Institute London are currently undertaking a Europe-wide research project about student feedback. The provision of appropriate feedback given in a timely fashion is paramount to the ongoing learning of undergraduate and postgraduate dental students. They are exploring the role that tutors and students have when supplying and receiving feedback. Traditionally the National Students' Survey (NSS) has been critical of feedback delivered to students, with respect to its quantity, quality, usefulness and timeliness.

The study is looking at the delivery and receipt of feedback from the student's perspective. Consequently the authors want to know if current dental students are satisfied with the style of feedback received from tutors, whether they always receive feedback, whether that feedback helps with future learning, who delivers it, and if it is appropriate and adequate.

The survey is open to all undergraduate and postgraduate students through the UK and Europe and the authors would be obliged if readers could complete the questionnaire which is available through the link https:// forms.gle/PbeGRmd7caH4FN3T7.

Further information is available through Dr Peter Fine at p.fine@ucl.ac.uk on behalf of co-authors Professors Chris Louca (University of Portsmouth, UK), Albert Leung (UCL Eastman Dental Institute, UK) and Dr Ingrid Tonni (University of Brescia, Italy). 